\title{
TRICHINELLA MURRELLI: PATHOLOGICAL FEATURES IN HUMAN MUSCLES AT DIFFERENT DELAYS AFTER INFECTION
}

\author{
DUPOUY-CAMET J.*, PAUGAM A.*, DE PINIEUX G.**, LAVARDE V.*** \& VIEILLEFOND A.*
}

\section{Summary :}

The authors describe the pathological aspects of muscles of three patients infected with Trichinella murrelli. Biopsies were carried out at various intervals. Six weeks after infection, the muscular larvae were not encapsulated whereas encapsulation was seen

10 weeks after infection. Six years after infection, the larvae were still alive in a nurse cell surrounded by a very thick capsule.

Fourteen years after infection, cuticular larvae remnants were seen in degenerating nurse cells. The late encapsulation of Trichinella murrelli in human muscles could explain some clinical differences noticed during the outbreak during which these three patients were infected.

KEY WORDS : Trichinella murrelli, human pathology, muscle biopsy.

T Trichinella murrelli is a new species previously identified as the sylvatic isolate Trichinella T5 (Pozio et al., 2000). Briefly, T. murrelli $\mathrm{n}$. $\mathrm{sp}$ is characterised by its distribution in temperate areas of the Neartic region, by a delayed nurse cell development in parasitized muscles and no resistance to freezing. This parasite is found in the wildlife (bears, racoons, foxes) of Illinois, Indiana and the Appalachian mountains of Pennsylvania. Contrary to Trichinella spiralis, this parasite has a low reproductive capacity in rats and pigs. The precise typing of this parasite is now possible by DNA studies. The name murrelli was chosen in honour of K.D. Murrell for his outstanding contributions in the field of immunology and epidemiology of Trichinella. One of us had the opportunity to describe a human outbreak due to $T$. murrelli related to horsemeat consumption which occurred in France in 1985. Four hundred thirty one cases were identified and the

\footnotetext{
* Laboratoire de Parasitologie, Hôpital Cochin, Université René Descartes, 27, rue du Faubourg Saint-Jacques, 75014 Paris, France.

** Laboratoire d'Anatomopathologie, Hôpital Cochin,, Université René Descartes, 27, rue du Faubourg Saint-Jacques, 75014 Paris, France.

*** Laboratoire de Microbiologie, Hôpital Européen Pompidou, 20, rue Leblanc, 75015 Paris, France.

Correspondence: J. Dupouy-Camet, C.H.U. Cochin, 27, rue du Faubourg Saint-Jacques, 75014 Paris, France.

Tel.: 0158412251 - Fax 0158412247.

e-mail : jean.dupouy-camet@cch.ap-hop-paris.fr
}

horse carcass was imported from Connecticut, USA. (Ancelle et al., 1988). Several muscle biopsies were performed during and after the outbreak and we will describe here the pathological aspects of T. murrelli infection in human muscles at different intervals after infection.

\section{MATERIALS AND METHODS}

M uscle biopsies were performed on two patients during the outbreak and six and 14 years after the infection in an other patient. The biopsies were processed by the usual procedures and the tissue sections were stained with hematoxilin and eosin before microscopic examination.

Case $n^{\circ} 1$ : Around six weeks after the presumed date of infection, a 86 years old male patient died from severe neurological complications. A few days after an acute diarrhoea, muscular pains and a severe encephalitis occurred. Before death, a muscle biopsy was sampled from the quadriceps. After death, muscular samples were fed to mice.

Case $\mathrm{n}^{\circ}$ 2: A muscle biopsy was performed on this 54 years old male patient to explore neurological symptoms, about ten weeks after the onset of the acute phase. This patient was treated during the acute phase of the disease with flubendazole $400 \mathrm{mg} / \mathrm{d}$ during 14 days.

Case $n^{\circ}$ 3: Six years after the outbreak, a biopsy was performed on a 37 years old male patient who had persistent muscular pains. This patient was treated during the acute phase of the disease with flubendazole $400 \mathrm{mg} / \mathrm{d}$ during 14 days and he took during the following years several regimens of flubendazole (cumulative dose of $12 \mathrm{~g}$ ). After the biopsy, he received thiabendazole $(25 \mathrm{mg} / \mathrm{kg})$ for ten days and then albendazole $(15 \mathrm{mg} / \mathrm{kg})$ for 15 days. These treatments did not significantly improve the muscular pains. Seven years later ( 14 years after the outbreak), he was operated for a necrosis of the femoral head and hip replacement. At this occasion, a new muscle biopsy was performed. 


\section{RESULTS}

Case $n^{\circ} 1$ : The pathological study of the biopsy carried out six weeks after infection, showed a fully developed muscular larva without encapsulation in the muscle (Fig. 1). The cytoplasm of the muscular fibre was modified with a disappearance of myofilaments and presence of enlarged nuclei. The larva was apparently migrating in the whole length of the muscular fibre. Inflammatory cells infiltrates were seen around the parasitized muscular fibre and around some adjacent non-parasitized muscular fibres. The muscles samples taken at necropsy were examined after compression between two glass slides and a free non encapsulated larva was observed. These samples, fed to mice, led to obtain an isolate which was identified as Trichinella T5 (Dupouy-Camet, 1993) and is

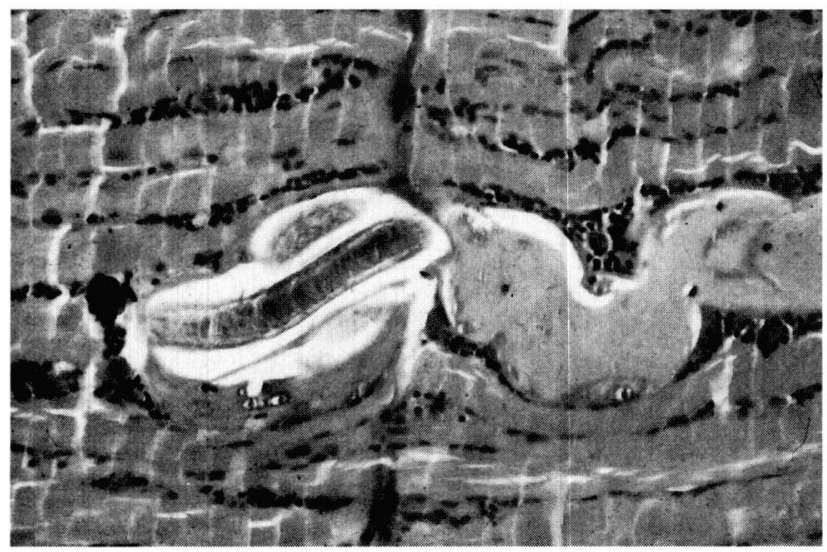

Fig. 1. - Longitudinal section of a muscle biopsy performed in the quadriceps (case $n^{\circ} 1$ ). Trichinella larva is inside a transformed muscular cell surrounded with a polymorphic cell infiltrate. The larva is non encapsulated six weeks afer infection. Original magnification $\times 400$.

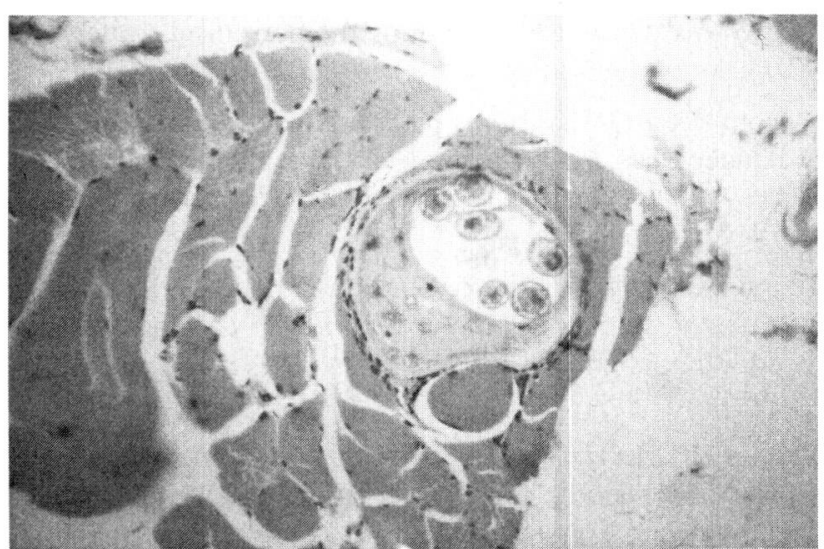

Fig. 2. - Cross section of a muscle biopsy (case $n^{\circ} 2$ ). Ten weeks after infection, the larva is now encapsulated. The cytoplasm of the nurse cell contains enlarged nuclei. Original magnification $\times 400$. now kept in the Rome International reference Centre (MHOM/FR/85/ISS103).

Case $\mathrm{n}^{\circ} 2$ : Ten weeks after infection, the larva was encapsulated in a modified muscular fibre (giving a typical aspect of nurse cell) and surrounded with a cellular infiltrate (Fig. 2). On some sections (not shown), the cellular inflammatory infiltrate was very important.

Case $n^{\circ} 3$ : Six years after infection, the larva appeared still alive but surrounded by a very thick capsule. A slight inflammatory reaction was still present around the parasitized fibre (Fig. 3). Fourteen years after infection, though several sections were performed in the muscle sample, no living larvae could be found. Remains of nurse cells were observed with a preserved capsule but the cytoplasm of the nurse cell was either vacuolated with picnotic nuclei or invaded with inflammatory cells (Figs 4 and 5). Ghosts of cuticles were visible either in the vacuolated cytoplasm of the nurse cell or in a multinucleated giant cell.
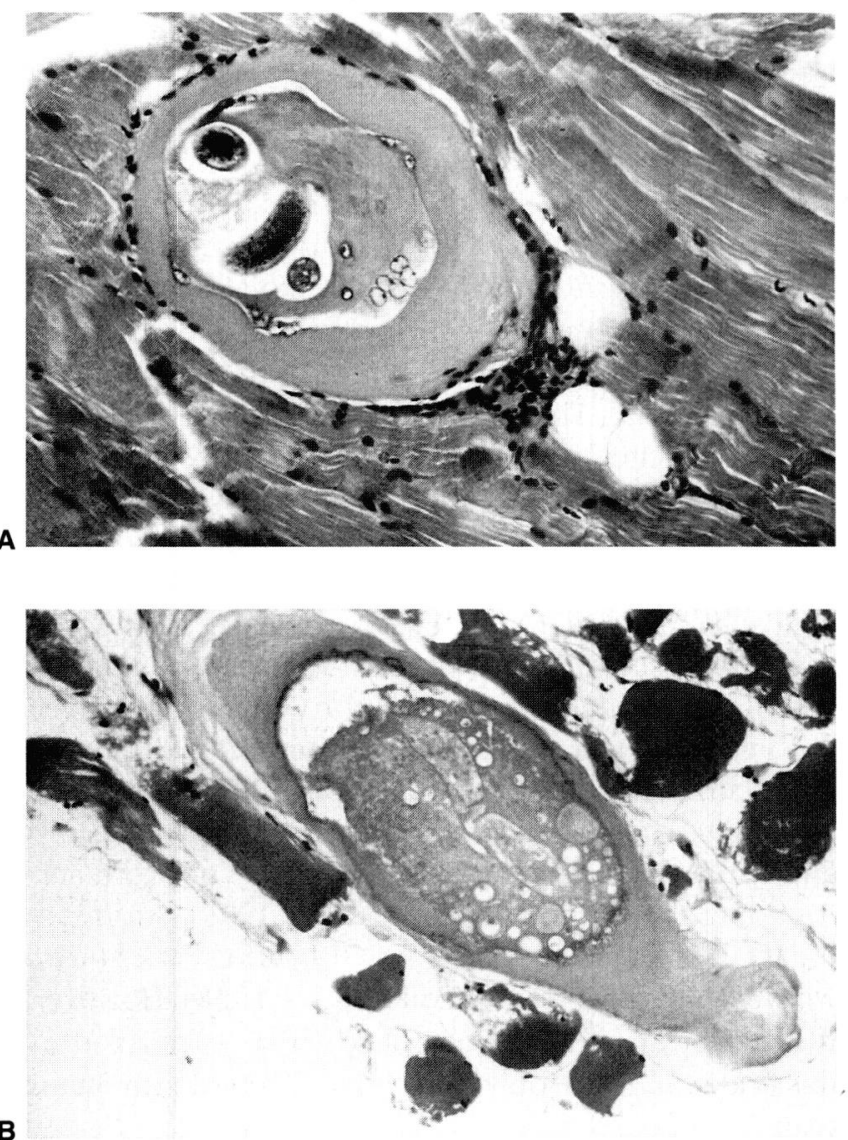

Fig. 3. - Transverse section of a muscle biopsy (case $n^{\circ} 3$ ).

A. Six years after the acute infection, presence of an encapsulated larva with a persisting inflammatory reaction around the very thick capsule. Original magnification $\times 400$.

B. Fourteen years after the acute infection, the nurse cell is degenerated with a vacuolated cytoplasm and picnotic nuclei. The capsule is still present and cuticular remnants of the worm can be seen. Original magnification $\times 400$. 


\section{DISCUSSION}

T The etiological agent of the outbreak was isolated from case $\mathrm{N}^{\circ} 1$ and its analysis showed antigenic and genomic differences with other isolates of Trichinella and particularly T. spiralis (Dupouy-Camet et al., 1988, Dick et al. 1990, Soulé et al., 1993, DupouyCamet et al., 1994). This isolate was finally identified in 1992 as Trichinella T5 (Dupouy-Camet, 1993) and, as mentioned above, Trichinella $\mathrm{T} 5$ has been recently reassessed at the species level as Trichinella murrelli (Pozio et al., 2000). The pathological aspects of the muscular biopsy performed at six weeks post infection were similar to those observed with $T$. pseudospiralis infection (Ranque et al., 2000) showing non encapsulated mature larvae migrating in the muscular fibres. However, at 10 weeks post infection, larvae were encapsulated. This delayed encapsulation of T. murrelli has also been observed experimentally. In Swiss mice, encapsulation began at 16 days post-infection for Trichinella spiralis and at 24 days for T. murrelli. At 37 days post-infection, $100 \%$ of T. spiralis muscle larvae were encapsulated whereas only $63-68 \%$ of T. murrelli larvae had formed capsules at 51 days postinfection; the remaining larvae did not exhibit nurse cell formation throughout the four months observation period (Pozio et al., 1992). The delayed encapsulation of Trichinella murrelli could explain the clinical particularities observed during this outbreak in which $44 \%$ of the patients had a skin rash and only $58 \%$ a facial oedema. The non encapsulated larvae could shed in the circulatory system allergenic substances responsible for this rash. Not a lot is known about the pathophysiology of the facial oedema (Kociecka, 1989) but it could be a consequence of a generalised vasculitis similarly to what is observed in connective tissue diseases. In these diseases, increased levels of vascular endothelial growth factor (VEGF) have been reported (Kikuchi et al., 1998). An important secretion of vascular endothelial growth factor (VEGF) is induced by Trichinella spiralis in the encapsulating nurse cell and leads to the formation of a capillary network surrounding the nurse cell (Capo et al., 1998). An hypothetical lower secretion of VEGF during Trichinella murrelli infections could lead to less oedemas. However, these clinical particularities need to be confirmed as this outbreak is the only one so far reported in humans with this species.

The growth and development in the muscle cells of Trichinella larvae induces a variety of important morphologic, biochemical and functional alterations. Before and during encapsulation, there is an inflammatory reaction characterised by the involvement of single muscle fibres, with a basophilic transformation of the muscular fibre and cellular infiltrates consisting of polymorphonuclear cells, mainly eosinophils, lymphocytes, and a few histiocytes. The long-term fate of the larvae is death and eventual calcification (Weatherly, 1983). The delay of survival of Trichinella larvae in human muscles is discussed. Gullotta \& Froscher (1983) reported the finding of living larvae in muscular biopsies 13 to 35 years after infection. These cases reported in German patients were probably due to Trichinella spiralis infections. In a pathological study of the muscles tissues performed in five Polish patients (Kociecka et al., 1997), Trichinella larvae with "traits of calcification" were observed in two patients, two and six years after the infection. In our case, no living larvae were seen in the biopsies performed 14 years after infection. This could reflect the natural evolution of $T$. murrelli larvae in human muscles but also be a consequence of the thiabendazole and albendazole regimens prescribed six years after the infection. To conclude, the encapsulation of T. murrelli in human muscles occurs between six and 10 weeks after the infection and the larvae can survive at least six years after infection.

\section{REFERENCES}

Ancelle T., Dupouy-Camet J., Bougnoux M., Fourestie V., PettT H., Mougeot G., Nozais J. \& Lapierre J. Two outbreaks of trichinosis caused by horsemeat in France in 1985. Am.J Epidemiol, 1988, 127, 1302-1311

CAPO V.A, Despommier D.D. \& POlverre R.I. Trichinella spiralis: vascular endothelial growth factor is up-regulated within the nurse cell during the early phase of its formation. J Parasitol, 1998, 84, 209-214.

Dick T.A., Devos T. \& Dupouy-Camet J. Identification of two isolates of Trichinella recovered from humans in France. J Parasitol, 1990, 76, 41-44.

Dupouy-Camet J., Bougnoux M.E., Ancelle T., Fagard R. \& LAPIERRE J. Antigenic characteristics of two strains of Trichinella spiralis isolated during the horsemeat-related outbreaks of 1985 in France. Parasitol Res, 1988, 75, 79-80.

Dupouy-CAmET J. Caractères parasitologiques, pathogéniques, antigéniques, isoenzymatiques et génomiques de deux isolats de Trichinella d'origine équine. PhD thesis, Paris XII University, 1993.

Dupouy-Camet J., Robert F., Guillou J.P., Vallet C., Perret C. \& Soulé C. Identification of Trichinella isolates with random amplified polymorphic DNA markers. Parasitol Res, 1994, 80, 358-360.

Kikuchi K., Kubo M., Kadono T., Yazawa N., Ihn H. \& TAMAKI K. Serum concentrations of vascular endothelial growth factor in collagen diseases. Br J Dermatol, 1998, 139, 1049-1051.

Kociecka W., Mrozewicz B. \& Gustowska L. Clinical aspect of late sequellae of trichinellosis. Wiad Parazytol, 1997, 43, 309-311. 
KOCIECKA W. Pathophysiological aspects of Trichinella infection in man. Ann Ist Super Sanita, 1989, 25, 635-640.

Pozio E., la Rosa G., Rossi P. \& Murrell D. Biological characterisation of Trichinella isolates from various host species and geographical regions. J Parasitol, 1992, 78, 647653.

Pozio E. \& LA RosA G. Trichinella murrelli n.sp.: etiological agent of sylvatic trichinellosis in temperate areas of north America. J Parasitol, 2000, 86, 134-139.

Gullotta F. \& Froscher W. Chronische Trichinose und neuromuskuläre Erkrankungen. Morphologische und pathogenetische Aspekte. Arch Psychiatr Nervenkr, 1983, 232, 479-487.

Ranque S., Faugere B., Pozio E., la Rosa G., Tamburrini A., Pellissier J.F., Brougui P. Trichinella pseudospiralis outbreak in France. Emerg Infect Dis, 2000, 6, 543-547.

Soulé C., Guillou J.P., Dupouy-Camet J., Vallet C. \& Pozio E. Differentiation of Trichinella isolates by polymerase chain reaction. Parasitol Res, 1993, 79, 461-465.

Weatherly N. Anatomical Pathology. In: "Trichinella and Trichinosis" Campbell W.C. (ed.). New York and London, Plenum Press, 1983, 173-208. 